JHR

32,2

Received 1 May 2017 Accepted 1 August 2017

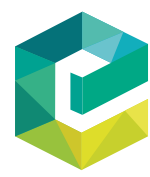

Journal of Health Research Vol. 32 No. 2, 2018 pp. $172-178$ Emerald Publishing Limited 2586-940X DOI 10.1108/JHR-01-2018-017

\section{An investigation into respiratory health problems of workers at stone crushing industries in Bangladesh}

\author{
Ehtesham Kabir \\ National Newborn and Child Health Cell, \\ Integrated Management of Childhood Ilness Section, \\ Directorate General of Health Services, Dhaka, Bangladesh \\ Aminul Islam \\ Department of Journalism, Communication and Media Studies, \\ Varendra University, Rajshahi, Bangladesh, and \\ Md. Taufikuzzaman \\ Department of Sociology, Varendra University, Rajshahi, Bangladesh
}

\begin{abstract}
Purpose - Occupational exposure to dust is a major health and safety concern for workers in developing countries. Such laborers are often exposed to dust without being aware of its threat to their health. In the process of crushing stone, mineralogical materials are released into the environment. The material includes dust, fumes, ashes or other industrial waste which may constitute toxic elements. The purpose of this paper is to investigate the respiratory health problems of stone crushing industry workers in Bangladesh.

Design/methodology/approach - This cross-sectional descriptive research study was conducted by adopting a multi-method approach. Data were collected by use of a questionnaire survey, focus group discussions, in-depth interview and spirometric examinations. Focus group discussions and questionnaire surveys were conducted among 240 workers. The respondents were divided in six groups for the spirometric examination. The questionnaire was formulated by following standards set by the American Thoracic Society Division of Lung Disease questionnaire and European Coal and Steel Community. Data on respondent's height, weight and smoking habits were collected by using a structured checklist. Meanwhile, lung functions were assessed by spirometry. A Statistical Package for Social Sciences was used to analyze the data.

Findings - The results show that there was a significant relation between respiratory problems and inhalation of dust and particulate matter and cigarette smoking. It also shows that coughing was the most common problem among the respondents. The majority of respondents suffered from obstructive types of respiratory problems.

Originality/value - Findings of the study reveals that chronic exposure to dust at stone crushing plants increases the risk of respiratory problems and the impaired lung function of workers. It also reveals that there is a significant relation between respiratory problems and inhalation of dusts and cigarette smoking. Raising awareness about health risks amongst workers could reduce these health hazards. The government should make a national policy for the prevention, control and elimination of silica exposure and silicosis. The results would help to raise awareness of the issue. Finally, it would raise awareness on respiratory health problems of workers at stone crushing industries in Bangladesh and help the government to make a policy for the prevention, control and elimination of silica exposure and silicosis, and thus enhancing public health policy and practices in the country.
\end{abstract}

Keywords Bangladesh, Respiratory problems, Spirometry, Silicosis, Lung fibrosis

Paper type Short report

(c) Ehtesham Kabir, Aminul Islam and Md. Taufikuzzaman. Published in the Journal of Health Research. Published by Emerald Publishing Limited. This article is published under the Creative Commons Attribution (CC BY 4.0) licence. Anyone may reproduce, distribute, translate and create derivative works of this article (for both commercial \& non-commercial purposes), subject to full attribution to the original publication and authors. The full terms of this licence may be seen at http://creativecommons.org/licences/ by/4.0/legalcode 


\section{Introduction}

Occupational exposure to dust is a major concern for the health safety of workers in developing countries. The workplace health hazard and safety issues get less attention in public health discourse, academic debates and health policies in Bangladesh. This study investigates the respiratory health problems among workers in stone crushing industries in Lalmonirhat district, about $360 \mathrm{~km}$ north of Dhaka, the capital of the country. It also explores the extent and nature of respiratory health problems among workers.

Inhalation of dust containing silica causes silicosis and lung fibrosis[1,2]. In the process of crushing stone, mineralogical materials are released into the environment as dust, fumes, ashes or other industrial waste which may constitute toxic elements and may cause a health risk to the workers. Several studies[3-6] found that there is a significant association between loss of lung function and cumulative respirable dust exposure. Chronic exposure to quarry dust deteriorates proper functioning of the lungs[7]. But impaired lung function-cigarette smokers are at higher risk[8]. Silica dust causes lung cancer[9]. There is a close relationship between the risk of lung cancer and exposure to silica and duration of exposure[10]. But the risk of getting lung cancer may be restricted to persons with silicosis and is not directly linked to silica dust. The objectives of this study were to find out the extent and nature of work-related respiratory health problems and spirometric abnormalities among stone crushing workers.

\section{Methods}

This cross-sectional descriptive research was conducted by adopting a multi-method approach. It was approved by the Ethical Review Committee from the National Institute of Preventive and Social Medicine. Data were collected by using a questionnaire survey, in-depth interview and spirometric examinations between July and August 2016.

Primarily, several in-depth interviews and group discussions were conducted at individual level and in-group among the workers who were at least 18 years of age, and involved in the job for at least 6 months without any gap at the plants. During the interviews and discussion, the workers were informed about the research details including aims and objectives, questionnaire information and spirometric examination procedures. Some 300 workers voluntarily agreed to participate in the research. Later, they were divided in six groups in order to better manage the coordination and analysis of the in-depth interview, group discussion and spirometric examination. Each of the groups consisted of 50 workers and investigated within their daily working hours. The group members were invited individually for the spirometric examination and completing the questioners within their scheduled time periods. On an average, 40 workers from each group took part in the examinations on each scheduled week. Finally, 240 workers took part in the research and completed the questionnaires. Information on awareness of health risks was collected through in-depth interviews and group discussion.

The questionnaire was formulated by following the standards set by the American Thoracic Society Division of Lung Disease questionnaire (ATS-DLD-78-A) and the European Coal and Steel Community[12]. The questionnaire focused on the socio-demographic characteristics, occupation details as well as the present and past respiratory problems of the respondents. A data collector was assigned to help them complete the questionnaires. Upon completing the questionnaires, an assistant technician collected data on height and weight with the height scale and weight machine. The data on respondent's height, weight and smoking habits were collected by using a standard checklist. After measuring the height and weight, the spirometry was performed by a trained technician. No instruction was given to the respondents on discontinuing any drugs (if any) for their respiratory problems. A stethoscope (Litman-II) was used for chest examination.

A portable Spirometer (Spirotel, Version: 3.2) was used in the study. The Spirometry Procedure Manual by Centers for Disease Control and Prevention[11] was followed for the
Respiratory health problems 
JHR

32,2

spirometric examination. During the procedure, respondents were told to continue with their medication for respiratory problems as advised by their physicians. Sitting in a fully upright position, each respondent was asked to place a mouthpiece attached to the spirometer in their mouth and make a tight seal with their lip. A nose clip was applied to ensure proper airflow in to the spirometer. Respondents were each asked to breathe normally and slowly blow out until their lungs were emptied of breath and then take another deep breath to fill up their lungs completely. As soon as the lungs were full, they were asked to blowout as fast as they could. This procedure was repeated three times in order to ensure best results for each participant. Through this procedure, the following outcomes were measured: forced vtal capacity $(\mathrm{FVC})$ - the amount of air that can be forced out from the lung after forced inhale of air; peak expiratory flow rate (PEFR) - how fast one can blow out air from the lungs; and finally, forced expiratory volume in first second (FEV1) - the volume of air that can be forced out in one second after taking a deep breath.

The calculation of FEV1/FVC allows the identification of obstructive or restrictive respiratory problems. An FEV1/FVC $<70$ percent where FEV1 is reduced more than FVC signifies an obstructive defect such as chronic obstructive pulmonary disease (COPD) and asthma. Whether an FEV1/FVC $>70$ percent where FVC is reduced more so than FEV1 signifies restrictive defects such as interstitial lung diseases (e.g. pulmonary fibrosis) and chest wall deformities.

A Statistical Package for Social Sciences (SPSS) was used to analyze the data. Earlier, the data were checked, verified and coded. For tabular chart and graphical representation, MS Word and MS Excel 2007 were used. Statistical tests were done depending on the distribution of data. The mean and standard deviation were calculated for all data.

\section{Results}

There are 26 stone crushing plants in Burimari Land Port area of Patgram upazila in Lalmonirhat. About 600 workers are engaged in the plants. Of them, 240 permanent workers took part in the research. The majority (48.80 percent) of the respondents were aged between 26 and 35 years. Of them, 76.70 percent were male and 23.30 percent were female. The majority of the respondents (52.50 percent) were smokers while 47.50 percent were non-smokers. It was found that 28.30 percent of respondents worked at stone crushing sites for 12 months or less; 32.50 percent worked for 13-36 months; 35.00 percent for 37-60 months; and 4.20 percent for more than 60 months. On average, the respondents worked at the plants for 34.18 months. Of them, 74.2 percent worked eight hours a day, while 20.00 percent worked for 10 hours and only 5.80 percent worked six hours a day. Overall, the findings show that coughing, shortness of breath, wheezing and tightness of chest are the main problems related to respiration developed in the respondent's body. According to Figure 1, coughing is

Figure 1.

Pattern of current respiratory health problems
Patern of respiratory health problems $(n=240)$

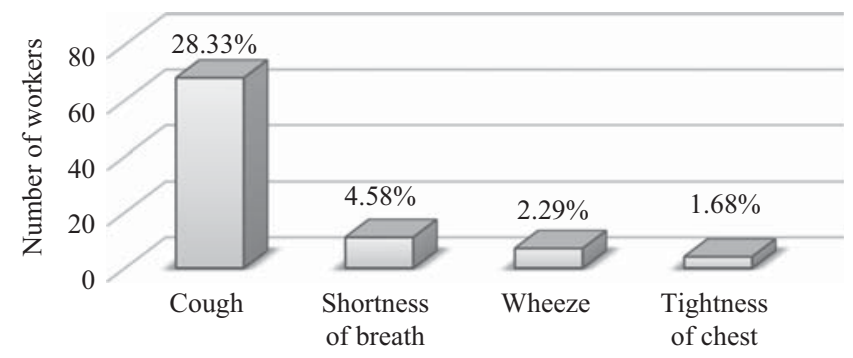

Types of problems 
the most prevalent respiratory problem among the workers. About 28.33 percent (68) of the workers suffered from cough, 4.58 percent (11) from shortness of breath, 2.29 percent (7) from wheeze and 1.68 percent (4) from tightness of chest. It is notable that 63.12 percent of the workers did not suffer from any respiratory problems.

Meanwhile, data in the Table I show that about 75.00 percent of the male workers suffer from obstructive types of respiratory problems and 66.67 percent suffer from restrictive respiratory problems, while only 25.00 percent of female workers suffer from obstructive types of respiratory problems.

There is significant relation between pulmonary function and duration of work. Table II shows that the Mean \pm SD FEV1 and FVC values for males were significantly decreased with duration of work, respectively, $3.31 \pm 0.31$ and $3.92 \pm 0.25 \mathrm{~L}$ for $\leqslant 12$ months; $3.02 \pm 0.33$ and $3.72 \pm 0.32 \mathrm{~L}$ for $13-36$ months; and $2.97 \pm 0.34$ and $3.74 \pm 0.33 \mathrm{~L}$ for $37-60$ months. While for females, the values were $2.28 \pm 0.17$ and $2.68 \pm 0.22 \mathrm{~L}$ for $\leqslant 12$ months; $2.06 \pm 0.34$ and $2.38 \pm 0.34 \mathrm{~L}$ for $13-36$ months; and $1.70 \pm 0.84$ and $2.31 \pm 0.29 \mathrm{~L}$ for $37-60$ months. However, the value of lung function test increased $(3.28 \pm 0.31$ and $3.85 \pm 0.17)$ among the group of workers engaged in their work for more than 60 months. It is possible that those workers suffered from respiratory problems and, therefore, could not continue their work in the same profession after 60 months, and the number of the respondents in this category was also not significant.

Smoking habits and personal protection against dust/use of PPE are also highly correlated with pulmonary functions. Table III shows that Mean \pm SD FEV1 and FVC values for male were also significantly decreased in smokers, i.e. $3.06 \pm 0.36$ and $3.76 \pm 0.33 \mathrm{~L}$; while for non-smokers, $3.10 \pm 0.36$ and $3.82 \pm 0.28 \mathrm{~L}$. The Mean \pm SD PEFR values for males were also significantly decreased in smoker, i.e. $481.08 \pm 36.299 \mathrm{~L} / \mathrm{min}$, while for non-smokers, $482.45 \pm 30.81 \mathrm{~L} / \mathrm{min}$. Mean \pm SD FEV1 and FEV1: FVC values for females were also significantly decreased in smokers, i.e. $2.04 \pm 0.39 \mathrm{~L}$ and $79.57 \pm 8.06$, while for nonsmokers, $2.16 \pm 0.29 \mathrm{~L}$ and $84.31 \pm 5.36$. The Mean \pm SD PEFR values for females were also significantly decreased in smokers, i.e. $329.71 \pm 43.21 \mathrm{~L} / \mathrm{min}$, while for non-smokers, $354.37 \pm 21.67 \mathrm{~L} / \mathrm{min}$.

\begin{tabular}{llrr} 
Characteristics & & $\begin{array}{c}\text { Obstructive type } \\
\%(n=16)\end{array}$ & $\begin{array}{c}\text { Restrictive type } \\
\%(n=6)\end{array}$ \\
\hline Sex & Male & $75.00(12)$ & $66.67(4)$ \\
Smoking habit & Female & $25.00(4)$ & $33.33(2)$ \\
& Smoker & $87.50(14)$ & $83.33(5)$ \\
Use of personal protection equipment (PPE), e.g. dust mask & Non-smoker & $12.50(2)$ & $16.67(1)$ \\
& PPE use & $25.00(4)$ & $83.33(5)$ \\
& PPE not use & $75.00(12)$ & $16.67 \%(1)$
\end{tabular}

Respiratory health problems

Table I.

Types and characteristics of the respondents having of respiratory problems

\begin{tabular}{|c|c|c|c|c|c|c|}
\hline$\underline{\text { Duration of work }}$ & Gender & $\begin{array}{c}\text { PEFR }(\mathrm{L} / \mathrm{min}) \\
\text { Mean } \pm \mathrm{SD}\end{array}$ & $\begin{array}{c}\mathrm{FEV}_{1}(\mathrm{~L}) \\
\text { Mean } \pm \mathrm{SD}\end{array}$ & $\begin{array}{c}\mathrm{FVC}(\mathrm{L}) \\
\text { Mean } \pm \mathrm{SD}\end{array}$ & $\begin{array}{l}\mathrm{FEV}_{1}: \mathrm{FVC} \\
\mathrm{Mean}_{ \pm} \mathrm{SD}\end{array}$ & \\
\hline \multirow[t]{2}{*}{$\leqslant 12$ months } & Male (39) & $471.28 \pm 25.46$ & $3.31 \pm 0.31$ & $3.92 \pm 0.25$ & $83.74 \pm 4.39$ & \\
\hline & Female (29) & $363.97 \pm 11.60$ & $2.28 \pm 0.17$ & $2.68 \pm 0.22$ & $84.83 \pm 2.56$ & \\
\hline \multirow{2}{*}{$13-36$ months } & Male (56) & $477.68 \pm 24.64$ & $3.02 \pm 0.33$ & $3.72 \pm 0.32$ & $80.61 \pm 4.75$ & \\
\hline & Female (22) & $347.73 \pm 21.81$ & $2.06 \pm 0.34$ & $2.38 \pm 0.34$ & $84.55 \pm 6.87$ & Table II. \\
\hline \multirow{2}{*}{$37-60$ months } & Male (79) & $484.28 \pm 40.88$ & $2.97 \pm 0.34$ & $3.74 \pm 0.33$ & $79.32 \pm 5.94$ & Mean values of \\
\hline & Female (5) & $293.40 \pm 22.39$ & $1.70 \pm 0.84$ & $2.31 \pm 0.29$ & $73.60 \pm 6.50$ & pulmonary functions \\
\hline \multirow[t]{2}{*}{$>60$ months } & Male (10) & $522.00 \pm 25.73$ & $3.28 \pm 0.31$ & $3.85 \pm 0.17$ & $81.10 \pm 2.28$ & in relation to duration \\
\hline & Female (0) & - & - & - & - & of work \\
\hline
\end{tabular}


JHR

32,2

176

Results of spirometric findings are shown in Figure 2. Among 240 respondents, 218 (90.80 percent) were normal, 16 respondents (6.70 percent) had developed obstructive types of respiratory problems and only 6 respondents (2.50 percent) developed restrictive types of respiratory problems.

\section{Discussion}

Findings show that coughing, shortness of breath, wheezing and tightness of chest are the main problems related to respiration developed in the workers' bodies. It also reveals that chronic exposure to dust at stone crushing plants increase the risk of respiratory problems and impaired lung function of workers. The prevalence of restrictive types of respiratory problem is higher compared to obstructive types of problems. Obstructive types of respiratory problems are developed due to COPD and silicosis. A simple chest X-ray can differentiate between COPD and silicosis. On the other hand, restrictive types of respiratory problems develop due to bronchial asthma, chronic bronchitis and other respiratory issues. According to the results, there is a significant relation between the pulmonary function of participants and duration of work. It also reveals that there is a significant relation between respiratory problems and inhalation of dusts and cigarette smoking, while smoking habits and personal protection against dust/use of PPE are also highly correlated with pulmonary functions. Additionally, occupational exposure to dust can also affect other organs. There is a possible link between dust inhalation and skin problems[13], cardiovascular deaths[14] and heart disease[15].

\begin{tabular}{llcccc}
\hline Characteristics & Gender & $\begin{array}{c}\text { PEFR (L/min) } \\
\text { Mean } \pm \text { SD }\end{array}$ & $\begin{array}{c}\mathrm{FEV}_{1}(\mathrm{~L}) \\
\text { Mean } \pm \mathrm{SD}\end{array}$ & $\begin{array}{c}\text { FVC (L) } \\
\text { Mean } \pm \text { SD }\end{array}$ & $\begin{array}{c}\mathrm{FEV}_{1}: \mathrm{FVC} \\
\text { Mean } \pm \mathrm{SD}\end{array}$ \\
\hline Smoking habits & Smoker: male (119) & $481.08 \pm 36.29$ & $3.06 \pm 0.36$ & $3.76 \pm 0.33$ & $80.74 \pm 5.40$ \\
& Smoker: female (7) & $329.71 \pm 43.21$ & $2.04 \pm 0.39$ & $2.54 \pm 0.35$ & $79.57 \pm 8.06$ \\
& Non-smoker: male (65) & $482.45 \pm 30.81$ & $3.10 \pm 0.36$ & $3.82 \pm 0.28$ & $80.75 \pm 5.39$ \\
Personal protection & Non-smoker: female (49) & $354.37 \pm 21.67$ & $2.16 \pm 0.29$ & $2.53 \pm 0.32$ & $84.31 \pm 5.36$ \\
& PPE use: male (48) & $502.92 \pm 31.28$ & $3.13 \pm 0.35$ & $3.77 \pm 0.31$ & $81.90 \pm 3.48$ \\
& PPE use: female (27) & $342.11 \pm 32.13$ & $2.04 \pm 0.36$ & $2.44 \pm 0.36$ & $82.04 \pm 7.69$ \\
& PPE not use: male (136) & $474.03 \pm 32.28$ & $3.05 \pm 0.36$ & $3.78 \pm 0.32$ & $80.34 \pm 5.87$ \\
& PPE not use: female (29) & $359.83 \pm 14.91$ & $2.24 \pm 0.19$ & $2.61 \pm 0.25$ & $85.28 \pm 2.83$
\end{tabular}

Figure 2.

Types of respiratory problem among respondents

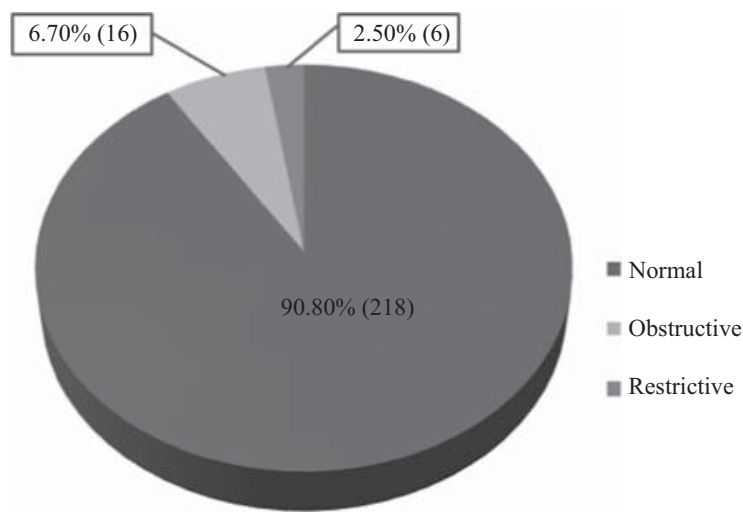


Raising awareness and taking safety measures could reduce the health hazard presented. Through this research, it is hoped that discussion about the issue may be initiated to help the government make a national policy for the prevention, control and elimination of silica exposure and silicosis, and thus enhance public health policy and practices in the country.

However, this study had some limitations. These include the following: the dust concentration within the industrial environment was not measured due to lack of instruments and resources; verification of the use of PPE and confirmation of the length of employment of individual workers was not possible due to non-availability of records; respiratory symptoms were totally subjective; no chest X-rays were done; and the type of silica in the workplace was not evaluated.

\section{Conclusion}

Chronic exposure to dust at stone crushing plants may increase the risk of respiratory problems and impaired lung function. Employers lacking in appropriate safety measures against dust are at higher risk of the problem. The risk is high among the workers who smoke cigarettes. Exposure to dust and smoking for long periods of time can develop silicosis in the human body. The symptoms of silicosis include fever, cough and shortness of breath, weight loss, respiratory insufficiency, heart failure and, finally, death. It may often cause chronic cough-like symptoms, but not tuberculosis. Raising awareness of the workers could reduce the health hazard of the worker. The government should make a national policy for the prevention, control and elimination of silica exposure and silicosis so that primary prevention can be ensured. Raising awareness of the workers and plant owners could reduce the health hazard. The government should make a national policy for the prevention, control and elimination of silica exposure and silicosis. The results would help to raise awareness of the issue.

\section{References}

1. Ding M, Chen F, Shi X, Yucesoy B, Mossman B, Vallyathan V. Diseases caused by silica: mechanisms of injury and disease development. Int Immunopharmacol. 2002 Feb; 2(2-3): 173-82.

2. Castranova V, Vallyathan V. Silicosis and coal workers' pneumoconiosis. Environ Health Perspect. 2000 Aug; 108(Suppl 4): 675-84.

3. Ehrlich RI, Myers JE, te Water Naude JM, Thompson ML, Churchyard GJ. Lung function loss in relation to silica dust exposure in South African gold miners. Occup Environ Med. 2011 Feb; 68(2): 96-101, doi: 10.1136/oem.2009.048827

4. Kuempel ED, Wheeler MW, Smith RJ, Vallyathan V, Green FH. Contributions of dust exposure and cigarette smoking to emphysema severity in coal miners in the United States. Am J Respir Crit Care Med. 2009 Aug; 180(3): 257-64, doi: 10.1164/rccm.200806-840OC

5. Rees D, Murray J. Silica, silicosis and tuberculosis. Int J Tuberc Lung Dis. 2007 May; 11(5): 474-84.

6. Soutar CA, Hurley JF. Relation between dust exposure and lung function in miners and ex-miners. Br J Ind Med. 1986; 43(5): 307-20.

7. Isara AR, Adam VY, Aigbokhaode AQ, Alenoghena IO. Respiratory symptoms and ventilatory functions among quarry workers in Edo state, Nigeria. Pan Afr Med J. 2016; 23(212): doi: 10.11604/ pamj.2016.23. 212.7640

8. Nwibo AN, Ugwuja EI, Nwambeke NO, Emelumadu OF, Ogbonnaya LU. Pulmonary problems among quarry workers of stone crushing industrial site at Umuoghara, Ebonyi State, Nigeria. Int J Occup Environ Med. 2012 Oct; 3(4): 178-85.

9. Partanen T, Jaakkola J, Tossavainen A. Silica, silicosis and cancer in Finland. Scand J Work Environ Health. 1995; 21(S2): 84-6. 
10. Ulm K, Waschulzik B, Ehnes H, Guldner K, Thomasson B, Schwebig A, et al. Silica dust and lung cancer in the German stone, quarrying, and ceramics industries: results of a case-control study. Thorax. 1999 Apr; 54(4): 347-51.

11. Centers for Disease Control and Prevention (2011), Spirometry procedures manual. National Health and Nutrition Examination Survey (NHANES), Atlanta.

12. Tennant S, Szuster F. Nationwide monitoring and surveillance question development: Asthma. Public Health Information Development Unit, Adelaide; 2003.

13. Ugbogu OC, Ohakwe J, Foltescu V. Occurrence of respiratory and skin problems among manual stone-quarrying workers. Mera: African Journal of Respiratory Medicine. 2009 Mar; 23-6.

14. Brunekreef B, Forsberg B. Epidemiological evidence of effects of coarse airborne particles on health. Eur Respir J. 2005 Aug; 26(2): 309-18, doi: 10.1183/0903 1936.05.00001805

15. Sjögren B. Occupational exposure to dust: inflammation and ischaemic heart disease. Occup Environ Med. 1997 Jul; 54(7): 466-69.

\section{Corresponding author}

Aminul Islam can be contacted at: aminul@vu.edu.bd; aminul.vu@gmail.com

For instructions on how to order reprints of this article, please visit our website: 